\title{
Editorial \\ Introducing the Journal of Anomalous Experience and Cognition (JAEX)
}

\author{
Etzel Cardeña, Lund University
}

If you have published anything in an academic journal, your email is probably inundated with unctuous invitations to have your earth-shattering contribution published in the next issue of a journal whose title is almost the same as that of an established journal. These invitations are almost invariably written in poor English and, reading the small print, require that you send money for an almost instantaneous acceptance. It does not take a Sherlock Holmes to conclude that these are predatory attempts to exchange money for a minimal to non-existent peer-review. If you have done anything that can stand scrutiny, you can easily dismiss all of these "invitations." However, even some genuine journals are little more than business propositions for those at the top who use the work by writers and reviewers to pay for their salaries, not to mention journals that list under their criteria for acceptance that the paper not deal with "pseudoscience," without further clarification, allowing them to reject any piece they may disagree with, even if appropriately conducted, and persecute those who challenge them (Beall, 2017; Cardeña, 2015).

This leaves a considerably smaller group of journals that have professional and ethical standards and remain open to challenging publications, and a much smaller list of journals that may deal with the topics of JAEX (anomalous experience and cognition). Historically, during its initial years at the end of the $19^{\text {th }}$ century, the Society for Psychical Research covered the whole gamut of anomalous experiences and cognition, but soon areas such as hypnosis and dissociation detached themselves from association with their disreputable cousin, psi phenomena, a state of affairs that the just departed Carlos Alvarado questioned in many publications (e.g., Alvarado, 1989; see a special section of tributes in this issue).

The taboo against publishing research on anomalous experiences in mainstream journals and books went the way of disco music at the turn of the 21st century (e.g., 
Cardeña et al., 2000; Lommel et al., 2001), but not the one against works on anomalous cognition (Cardeña, 2015). Furthermore, specific anomalous experiences and anomalous cognition in general have remained in their particular niches, typically according to discipline (e.g., psychology, anthropology, parapsychology), and the product of this balkanization of discourse has produced isolated enclaves that would benefit enormously from knowledge of each other, as the paper in this issue by Tressoldi and Storm suggests. It is not only that aspects of anomalous experiences and cognition seem to overlap, but that even the study of anomalous experiences/alterations of consciousness would benefit from comparing commonalities and differences across them, such as those produced by psychedelics and near-death experiences. And, of course, different disciplines offer varying worthy perspectives that would benefit from a common basis of knowledge (cf. Cardeña \& Winkelman, 2011).

The Journal of Anomalous Experience and Cognition is launched as a forum for the presentation of new findings and theories, and the cross-fertilization across related topics and disciplines, while maintaining rigorous peer-reviewing standards and opening the results to all interested parties without any cost (i. e., it is a free, open access journal, based in a prestigious university, and with an authoritative editorial board). It thus joins the resistance against the increased monetarization and insularity of academic knowledge, while maintaining its independence from any organization's particular interests or biases (although the Parapsychology Foundation, to our delight, agreed to be JAEX's nominal publisher, it does not interfere with any editorial or financial decisions), unlike some of the niche journals.

This first issue includes an impressive array of papers, this time focused on anomalous cognition. Besides five research studies (including two exchanges between authors and reviewers), it contains tributes to the indefatigable historian and researcher Carlos Alvarado, book reviews, and a bibliography of recent publications.

If you are a researcher, theoretician, historian, humanist, or artist seriously interested in anomalous experiences and/or cognition, you need not look further for a journal that will welcome your submission. And if you are just a reader interested in areas of human functioning that have so far been mostly been neglected, you are equally welcome!

\section{References}

Alvarado, C. S. (1989). Dissociation and state-specific psychophysiology during the nineteenth century. Dissociation, 2(3), 160-168. 
Beall, J. (2017). What I learned from predatory publishers. Biochemia Medica, 27(2), 273.278.

Cardeña, E. (2015). The unbearable fear of psi: On scientific censorship in the 21st century. Journal of Scientific Exploration, 29, 601-620.

Cardeña, E., Lynn, S. J., \& Krippner S. (Eds.), Varieties of anomalous experience: Examining the scientific evidence. American Psychological Association. Doi: 10.1037/14258-000

Cardeña, E., \& Winkelman, M. (2011). Altering consciousness. Multidisciplinary perspectives. 2 Vols. Praeger.

Van Lommel, P., Wees R. V., Meyers, V., \& Elfferich, I. (2001). Near-death experience in survivors of cardiac arrest: A prospective study in the Netherlands. The Lancet 358(9298), 2039-2045. Doi: 10.1016/s0140-6736(01)07100-8 